\title{
Plasma Vitamin D and Biomarkers of Cardiometabolic Disease Risk in Adult Canadians, 2007-2009
}

Bibiana García-Bailo, MSc; Laura A. Da Costa, MSc; Paul Arora, MSc; Mohamed Karmali, MD; Ahmed El-Sohemy, PhD; Alaa Badawi, PhD

Suggested citation for this article: García-Bailo B, Da Costa LA, Arora P, Karmali M, El-Sohemy A, Badawi A. Plasma Vitamin D and Biomarkers of Cardiometabolic Disease Risk in Adult Canadians, 2007-2009. Prev Chronic Dis 2013;10:120230. DOI: http://dx.doi.org/10.5888/pcd10.120230 圈.

PEER REVIEWED

\section{Abstract}

\section{Introduction}

Vitamin D may modulate cardiometabolic disease risk, although the relationship has not been investigated in the general Canadian population. Understanding this relationship may inform public health strategies to curb the incidence of cardiometabolic disease in Canada and elsewhere. The objectives of this study were to examine the association between vitamin $\mathrm{D}$ and traditional and novel biomarkers of cardiometabolic disease and to describe the extent of the month-to-month fluctuations of vitamin D in the Canadian population.

\section{Methods}

We examined the association between plasma 25-hydroxyvitamin D and a range of cardiometabolic risk biomarkers in participants ( $n=1,928$; age range, $16-79$ years) from the Canadian Health Measures Survey. We conducted linear regressions analyses (adjusted for sex, waist circumference, physical activity, hormone use, and season) to assess the relationship between 25-hydroxyvitamin $\mathrm{D}$ and biomarkers of dysglycemia, dyslipidemia, and inflammation in the study population. We repeated analyses stratified by sex, and we evaluated monthly fluctuations in 25-hydroxyvitamin $\mathrm{D}$ in men and women.

\section{Results}

We observed wide month-to-month variations in 25-hydroxyvitamin D; fluctuations were more pronounced in men. Plasma 25-hydroxyvitamin D was inversely associated with insulin, insulin resistance, triglycerides, total cholesterol, low-density lipoprotein cholesterol, and the ratio of total to high-density lipoprotein cholesterol but not with fasting glucose, apolipoprotein A1, apolipoprotein B, C-reactive protein, fibrinogen, or homocysteine. This pattern varied between men and women.

\section{Conclusion}

Vitamin D may modulate various metabolic processes and may influence cardiometabolic disease risk in Canadians. These findings may have public health implications when recommending vitamin $\mathrm{D}$ for the prevention of cardiometabolic disease and related conditions.

\section{Introduction}

Cardiometabolic disease is characterized by dyslipidemia, dysglycemia, abdominal obesity, and hypertension (1). Novel biomarkers of risk, such as apolipoprotein (Apo) A1 and ApoB (2), and the inflammatory markers C-reactive protein (CRP), fibrinogen, and homocysteine (3-5), have been proposed. Inadequate vitamin D status has been associated with elevated cardiometabolic disease risk, although results are inconsistent, as evidenced by recent meta-analyses pooling multiple study populations (6-8). These inconsistencies may result partly from differences in sample size, dosage, geographic location, and disease progression across studies.

The prevalence of vitamin D insufficiency (plasma 25-hydroxyvitamin D [25(OH)D] $<50 \mathrm{nmol} / \mathrm{L}$ ) among Canadians is high (9). This high prevalence of insufficiency may result from a decreased ability to produce vitamin D endogenously 
during the winter months (10). Indeed, the proportion of vitamin D-insufficient individuals in the general Canadian population was higher in winter than in summer (9). Among elderly in the United States, seasonal variations in vitamin D were greater in men than women (11). Whether these sex-based differences have biologic relevance that may translate into effects on health outcomes is unknown. The possibility that the effects of vitamin D on cardiometabolic disease differ by sex warrants further study. Furthermore, describing how vitamin D levels fluctuate month-to-month may provide a basis for implementing public health strategies to increase $25(\mathrm{OH}) \mathrm{D}$ levels when deficiency is most acute.

Recent studies suggest an association between vitamin D status, metabolic syndrome, insulin resistance, and obesity among Canadians $(12,13)$. However, the relationship between 25(OH)D and individual biomarkers of cardiometabolic disease has not been explored in the Canadian population, and whether it differs by sex is unknown. Understanding the association between vitamin D and cardiometabolic risk in Canadians may provide a clearer understanding of how this micronutrient modulates cardiometabolic disease and may inform public health strategies to curb the incidence of cardiometabolic disease in Canada and elsewhere.

Our objectives were to examine the association between 25(OH)D and traditional and novel biomarkers of cardiometabolic disease and to describe the extent of the month-to-month fluctuations of $25(\mathrm{OH}) \mathrm{D}$ in a representative sample of the general Canadian population.

\section{Methods}

\section{Study design and population}

We used data from the Canadian Health Measures Survey (CHMS) cycle 3.1, a representative sample of Canadians aged 6 to 79 years in whom direct indicators of health and wellness were measured. Details of the sampling design and strategy, methods, and data collection have been published elsewhere (14). Data were collected between March 2007 and February 2009 at 15 sites selected by using a multistage sampling strategy. The sites were chosen to cover $96.3 \%$ of the Canadian population, excluding people living on Aboriginal Reserves, on Crown Lands, in institutions, in remote regions, and full-time members of the Canadian Forces. A total of 6,106 households of the 8,772 selected agreed to participate in this study, for a household response rate of $69.6 \%$. From the 7,483 people selected from these households, 6,604 (88.3\%) people agreed to respond to the study questionnaire; 5,604 (84.9\%) of the 6,604 agreed to provide physical measurements. The national response rate for this survey was $51.7 \%$. All participants provided written informed consent and the study was approved by the Health Canada Research Ethics Board. For this study, we excluded people younger than 16 years and nonfasting responders. This resulted in a sample size of 1,928 people, representing 25,057,060 Canadians.

\section{Biologic and anthropometric measures}

Details of the collection and handling of biological samples have been described elsewhere (15). Samples were analyzed for cardiometabolic biomarkers, including glucose, fasting insulin, CRP, fibrinogen, homocysteine, triglycerides, total cholesterol, high-density lipoprotein cholesterol (HDL-C), low-density lipoprotein cholesterol (LDL-C), and ApoA1 and ApoB at the Health Canada Laboratory, Bureau of Nutritional Sciences, Nutrition Research Division, by using standard operating procedures. We calculated the ratio of total to HDL-C from measured values for total cholesterol and HDL-C. We calculated the homeostasis model of insulin resistance (HOMA-IR) from fasting measures of insulin $(\mu \mathrm{U} / \mathrm{mL})$ and glucose $(\mathrm{mmol} / \mathrm{mL})$ as insulin multiplied by glucose and divided by 22.5. Plasma 25(OH)D was measured by chemiluminescence assay by using the Liaison 25-hydroxyvitamin D Total assay (Diasorin, Ltd, Stillwater, Minnesota). Within-run and between-run coefficients of variation (CVs) for this assay ranged between $3.2 \%$ and $8.5 \%$ and between $6.9 \%$ and $12.7 \%$, respectively, based on preliminary testing using external quality controls from BioRad (BioRad Laboratories, Ltd, Mississauga, Ontario) and Diasorin. Samples analyzed by Health Canada were within these ranges.

We derived body mass index (BMI) as weight $(\mathrm{kg})$ divided by height $\left(\mathrm{m}^{2}\right)$ for measured height and weight. Waist circumference was measured by using a measuring tape at the midpoint between the last floating rib and the top of the iliac crest in the midaxillary line. Systolic and diastolic blood pressures were measured by using BP-TRU automated oscillometric devices (BP-TRU Medical Devices, Ltd, Coquitlam, British Columbia). Daily energy expenditure was calculated from self-reported leisure time physical activities during the past 3 months. A person's self-reported race was classified into 1 of 3 groups: white, Asian (Korean, Filipino, Japanese, Chinese, South Asian, Southeast Asian, Arab, and West Asian), and other (African Canadian, Latin American, and people of mixed ancestry). Self-reported medication use was collected and coded by using the American Hospital Formulary Service drug code. Subjects were dichotomized (yes/no) on the basis of use of hormones and synthetic substitutes in the previous month. The types of medications included in this categorization included hormonal contraceptives, androgens, estrogens, insulin, and thyroid hormones.

\section{Statistical analyses}


We performed all statistical analyses by using survey procedures in SAS (version 9.2, SAS Institute Inc, Cary, North Carolina). We set the $\alpha$ error at .05, and we report 2-sided $P$ values. We considered a $P$ value of $\leq .05$ significant. To account for the complex survey design, we applied bootstrap weights for variance estimates, sampling weights for point estimates, and 11 degrees of freedom. We examined the distributions of continuous variables by plotting histograms and natural log or square-root transformed skewed variables as needed before analysis to improve linearity of relationships and normality of residuals. We examined subject characteristics, including biomarkers of cardiometabolic disease, by sex. We used $t$ tests to examine the association between continuous variables, and $\chi^{2}$ tests to examine race and hormone use by sex. We plotted unadjusted weighted mean plasma 25(OH)D levels by month of clinic visit and by sex on a single graph to examine month-to-month variation in circulating vitamin $\mathrm{D}$ levels in men and women. We produced unadjusted weighted mean levels of cardiometabolic biomarkers by quartiles of 25(OH)D. We conducted linear regression models examining the linear association between cardiometabolic biomarkers and plasma levels of 25(OH)D adjusted for sex, waist circumference, physical activity, hormone use, and season of clinic visit to produce $\beta$ coefficients and the associated $P$ values. We dropped age from regression models because of multicolinearity with waist circumference. We also dropped race from the models because of the heterogeneous nature and small sample size of the nonwhite group. We repeated analyses stratified by sex.

\section{Results}

Anthropometric measures and mean levels of physical activity were significantly lower among women than men $(P$ $\leq$.002) (Table 1). Mean levels of glucose, HOMA-IR, homocysteine, triglycerides, LDL-C, total: HDL-C, and ApoB were significantly lower among women than men; levels of CRP, fibrinogen, HDL-C, total cholesterol, and ApoA1 were significantly higher among women than men $(P \leq .05)$.

Mean plasma 25(OH)D levels varied by month of clinic visit among men and women (Figure). Concentrations of 25 $(\mathrm{OH}) \mathrm{D}$ were highest from June through August, and lowest in January and February in both sexes. Concentrations of 25(OH)D fluctuated seasonally in both men and women, but the extent of fluctuation observed was greater among men than women; plasma 25(OH)D concentrations in men ranged from $53 \mathrm{nmol} / \mathrm{L}$ to $80 \mathrm{nmol} / \mathrm{L}$. Mean 25(OH)D concentrations in women ranged only from $62 \mathrm{nmol} / \mathrm{L}$ to $75 \mathrm{nmol} / \mathrm{L}$.

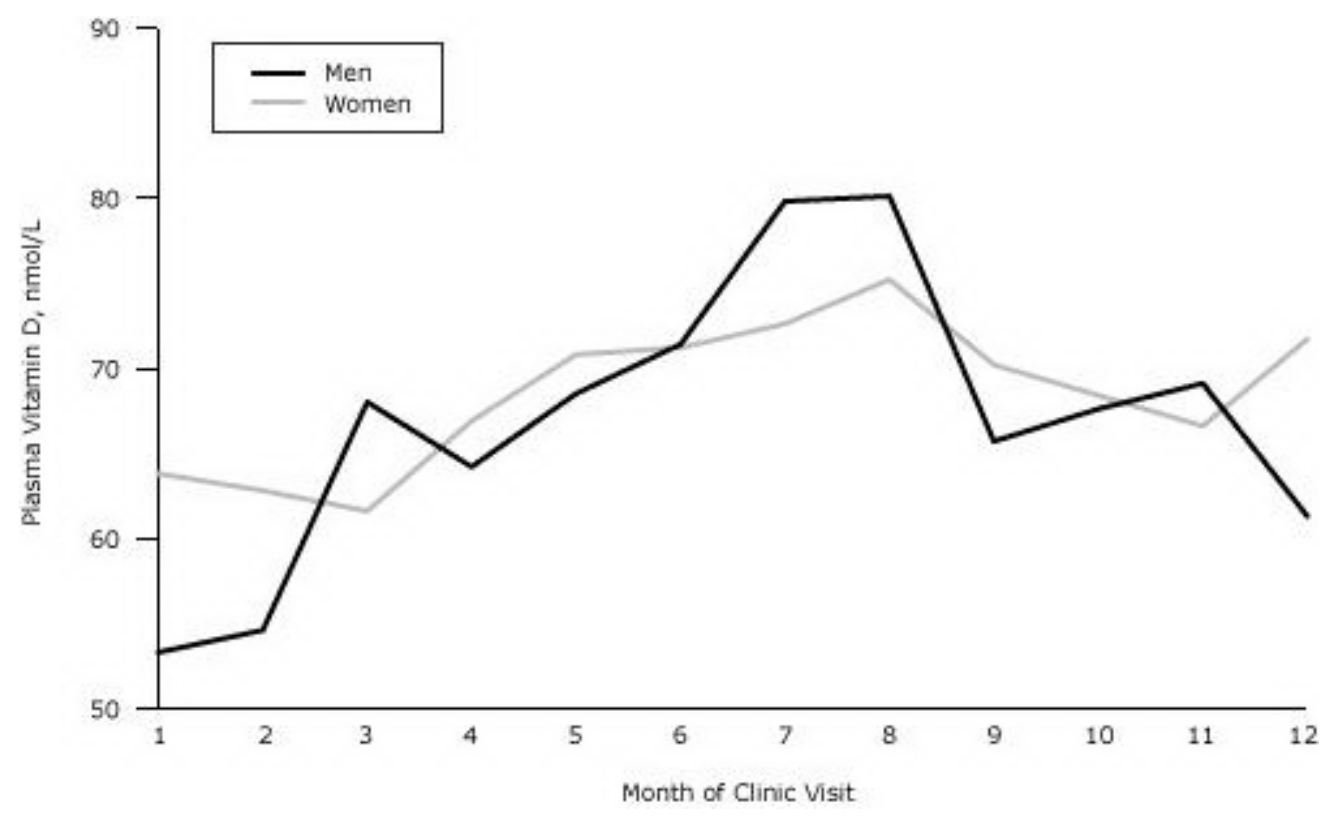

Figure. Mean plasma vitamin D, by month of clinic visit and sex, Canadian Health Measures Survey, 2007-2009. [A tabular version of this figure is also available.]

Mean levels of cardiometabolic biomarkers by quartiles of plasma 25(OH)D are shown in Table 2. Significant inverse linear associations were noted between plasma 25(OH)D and insulin, HOMA-IR, triglycerides, total cholesterol, LDL$\mathrm{C}$, and total cholesterol:HDL-C. No significant linear associations with plasma 25(OH)D were noted for glucose, HDLC, ApoA1, ApoB, CRP, fibrinogen, and homocysteine.

The relationship between 25(OH)D and cardiometabolic biomarkers in men and women separately is shown in Table 3. Among men, plasma 25(OH)D was inversely associated with insulin, HOMA-IR, and triglycerides. Among women, plasma 25(OH)D was inversely associated with insulin, HOMA-IR, total cholesterol, LDL-C, and total cholesterol:HDL -C. We noted a trend suggesting that $25(\mathrm{OH}) \mathrm{D}$ may be a stronger predictor of fasting insulin levels and HOMA-IR 
among men than women (insulin: $\beta=-0.21$ among men vs -0.13 among women; HOMA-IR: $\beta=-0.24$ among men vs -0.14 among women). However, for both of these biomarkers, the $95 \%$ confidence intervals for the $\beta$ coefficients from each sex overlapped (data not shown), indicating that the trend did not reach significance.

\section{Discussion}

We examined the association between vitamin $\mathrm{D}$ and traditional and novel biomarkers of cardiometabolic disease and found that it was inversely associated with insulin, insulin resistance, triglycerides, total cholesterol, LDL-C, and the ratio of total cholesterol to HDL-C, but not with fasting glucose, ApoA1, ApoB, CRP, fibrinogen, or homocysteine. This pattern varied between men and women.

We recently reported an inverse association between plasma 25(OH)D and metabolic syndrome risk (12) and obesity (13) in Canadians. However, to our knowledge, this study is the first to examine the association between vitamin D and individual biomarkers of cardiometabolic risk in the general Canadian population. We observed inverse associations between 25(OH)D and several traditional cardiometabolic risk factors, such as insulin, HOMA-IR, and biomarkers of lipid metabolism. Our findings are in agreement with previous reports that have associated low 25(OH)D with worsened levels of biomarkers of glycemic control and lipid metabolism $(12,16)$. Considering the widespread prevalence of vitamin D insufficiency in Canada and other countries around the world, understanding the degree to which low nutritional status of this vitamin affects disease-associated processes is key toward informing recommendations, both at the individual and the population levels, to obtain adequate vitamin D. Although our findings are cross-sectional, together with previous research conducted in Canada and elsewhere $(8,12,16-18)$ they suggest that an adequate vitamin D status may help prevent the development of cardiometabolic disease-related processes.

Evidence from in vitro studies suggests a role for vitamin D in improving insulin secretion and sensitivity (19,20). However, associations between $25(\mathrm{OH}) \mathrm{D}$ and markers of glycemic control in humans have been inconsistent $(16,17,21,22)$. The discrepancies may result from small sample sizes and from differences in racial background and disease status of the subjects assessed. We recently reported an inverse association between 25(OH)D and insulin resistance, as measured by HOMA-IR, in people without diabetes from the general Canadian population (12). As this study indicates, the inverse association between 25(OH)D and HOMA-IR is also present when people with diabetes are included in the analysis. Overall, these observations suggest a role for $25(\mathrm{OH}) \mathrm{D}$ in modulating glycemic responses, both in healthy people and in those who have impaired glycemic control. These findings may have public health implications and suggest that vitamin D supplementation may be used both in cardiometabolic disease prevention and in improving its complications. We noted a nonsignificant trend suggesting that 25(OH)D may be a stronger predictor of glycemic control biomarkers among men than women. This sex-based difference may be more apparent in populations with a greater incidence of cardiometabolic disease.

In this study, we reported inverse associations between 25(OH)D and triglycerides, total cholesterol, LDL-C, and total cholesterol:HDL-C in the overall population. When examined separately by sex, $25(\mathrm{OH}) \mathrm{D}$ was associated with triglycerides only among men. However, we also observed an inverse trend between 25(OH)D and triglycerides among women, although it failed to reach significance. Conversely, total cholesterol, LDL-C, and total cholesterol:HDL-C were inversely associated with $25(\mathrm{OH}) \mathrm{D}$ only among women. Again, similar inverse trends were observed among men, although they did not reach significance. Similar to our findings, the findings of many studies have reported inverse associations between 25(OH)D and various serum lipids $(18,21,23)$. Although the mechanistic link between 25(OH)D and lipid metabolism remains poorly understood, vitamin D has been proposed to modulate the transcription activity of an array of genes known to be involved in lipid metabolism $(24,25)$. In addition, previous research suggests that vitamin D may upregulate lipoprotein lipase activity in adipocytes, which would, in turn, result in decreased circulating triglyceride levels (26).

The consensus of available information from animal and cell culture models suggests that vitamin $\mathrm{D}$ modulates immune responses and may ameliorate inflammatory states (27). However, the association between serum 25(OH)D and biomarkers of inflammation, such as CRP and fibrinogen, in epidemiologic and clinical studies in humans has been inconsistent $(28,29)$. In this population-based cohort, after adjusting for relevant covariates, we observed no association between 25(OH)D and inflammatory biomarkers, either in the population as a whole or for either sex. However, it is possible that the anti-inflammatory effects of vitamin D are observed only in severely vitamin Ddeficient individuals or those with an immunocompromised status (3).

Previous studies have observed differences in levels of $25(\mathrm{OH}) \mathrm{D}$ by sex as well as differences in seasonal variation of circulating 25(OH)D $(9,11)$. Our results confirm these sex-based differences in seasonal fluctuations; men showed a greater degree of fluctuation than women ( $53-80 \mathrm{nmol} / \mathrm{L} \mathrm{vs} 62-75 \mathrm{nmol} / \mathrm{L}$, respectively). Although these differences can be a result of biologic or lifestyle factors, they may implicate a sex-related disparity in response to vitamin $\mathrm{D}$ intake. Elucidating whether these sex-associated month-to-month differences in vitamin D levels translate into different effects of vitamin D on disease-related processes in men and women warrants further study. 
Our study has limitations. Although representative of the racial distribution of the Canadian population, the small sample size in the nonwhite group prevented examining the associations assessed in this study in other race groups living in Canada. Other studies have reported variation in 25(OH)D levels across races, despite a similar intake of vitamin D intake from diet and supplements (9,30). Moreover, we have shown that Asian Canadians have significantly lower serum 25(OH)D than their white counterparts (12). Understanding the relationship between 25(OH)D and cardiometabolic risk factors across race groups in Canada may help develop intervention strategies targeted to vulnerable subgroups (ie, at-risk populations). Furthermore, we were unable to consider the potential effects on the associations we investigated of parathyroid hormone, calcium, phosphate, and fibroblast growth factor 23, all of which play central roles in vitamin D metabolism (10). Although waist circumference and physical activity are considered good indicators of visceral adiposity and fitness, respectively, we lacked direct measurements of the latter variables, which may play roles in the link between vitamin D and cardiometabolic disease. Finally, residual confounding and unaccounted influences of diet or genetic variations may affect some of the associations reported here.

We found inverse associations between $25(\mathrm{OH}) \mathrm{D}$ and biomarkers of cardiometabolic disease risk in a populationbased cohort representative of Canadian adults. We also observed month-to-month fluctuations in 25(OH)D and noted that plasma 25(OH)D levels fluctuated more widely in men than women. Our results contribute to an increasing body of evidence suggesting that vitamin D modulates processes associated with risk of cardiometabolic disease at the population level. These findings may have public health implications for recommending vitamin $\mathrm{D}$ to prevent cardiometabolic disease and related conditions.

\section{Acknowledgments}

Research in this manuscript was funded by the Public Health Agency of Canada. Dr El-Sohemy holds a Canada Research Chair in Nutrigenomics.

\section{Author Information}

Corresponding Author: Alaa Badawi, PhD, Office of Biotechnology and Population Health, Public Health Agency of Canada, 180 Queen St W, 11th Floor, Toronto, ON M5V 3L7. Telephone: +1-416-952-2230. E-mail: alaa.badawi@phacaspc.gc.ca.

Author Affiliations: Bibiana García-Bailo, Mohamed Karmali, Department of Nutritional Sciences, University of Toronto, and Office of Biotechnology and Population Health, Public Health Agency of Canada, Toronto, Canada; Laura A. Da Costa, Ahmed El-Sohemy, Department of Nutritional Sciences, University of Toronto, Toronto, Canada; Paul Arora, Office of Biotechnology and Population Health, Public Health Agency of Canada, and Dalla Lana School of Public Health, University of Toronto, Toronto, Canada.

\section{References}

1. Aschner P. Metabolic syndrome as a risk factor for diabetes. Expert Rev Cardiovasc Ther 2010;8(3):407-12. CrossRef圈 PubMed 圈

2. Pitsavos C, Panagiotakos DB, Skoumas J, Papadimitriou L, Stefanadis C. Risk stratification of apolipoprotein B, apolipoprotein A1, and apolipoprotein B/AI ratio on the prevalence of the metabolic syndrome: the ATTICA study. Angiology 2008;59(3):335-41. CrossRef 恩 PubMed 圈

3. Badawi A, Klip A, Haddad P, Cole DE, García Bailo B, El-Sohemy A, et al. Type 2 diabetes mellitus and inflammation: prospects for biomarkers of risk and nutritional intervention. Diabetes Metab Syndr Obes 2010;3:173-86. CrossRef 圈 PubMed 圈

4. Marti-Carvajal AJ, Sola I, Lathyris D, Salanti G. Homocysteine lowering interventions for preventing cardiovascular events. Cochrane Database Syst Rev 2009;4:CDo06612. PubMed 圈

5. Kadoglou NP, Avgerinos ED, Liapis CD. An update on markers of carotid atherosclerosis in patients with Type 2 diabetes. Biomarker Med 2010;4(4):601-9. CrossRef 圈 PubMed 圈

6. Pittas AG, Chung M, Trikalinos T, Mitri J, Brendel M, Patel K, et al. Systematic review: vitamin D and cardiometabolic outcomes. Ann Intern Med 2010;152(5):307-14. PubMed 圈

7. Elamin MB, Abu Elnour NO, Elamin KB, Fatourechi MM, Alkatib AA, Almandoz JP, et al. Vitamin D and cardiovascular outcomes: a systematic review and meta-analysis. J Clin Endocrinol Metab 2011;96(7):1931-42. CrossRef 国 PubMed 圈

8. Brondum-Jacobsen P, Benn M, Jensen GB, Nordestgaard BG. 25-hydroxyvitamin D levels and risk of ischemic heart disease, myocardial infarction, and early death: population-based study and meta-analyses of 18 and 17 studies. Arterioscler Thromb Vasc Biol 2012;32(11):2794-802. CrossRef 国 PubMed 圈 
9. Whiting SJ, Langlois KA, Vatanparast H, Greene-Finestone LS. The vitamin D status of Canadians relative to the 2011 Dietary Reference Intakes: an examination in children and adults with and without supplement use. Am J Clin Nutr 2011;94(1):128-35. CrossRef 圈 PubMed 圈

10. Norman AW. From vitamin D to hormone D: fundamentals of the vitamin D endocrine system essential for good health. Am J Clin Nutr 2008;88(2):491S-9S. PubMed 圈

11. Shoben AB, Kestenbaum B, Levin G, Hoofnagle AN, Psaty BM, Siscovick DS, et al. Seasonal variation in 25hydroxyvitamin D concentrations in the Cardiovascular Health Study. Am J Epidemiol 2011;174(12):1363-72. CrossRef 国 PubMed 圈

12. Brenner DR, Arora P, García-Bailo B, Wolever TM, Morrison H, El-Sohemy A, et al. Plasma vitamin D levels and risk of metabolic syndrome in Canadians. Clin Invest Med 2011;34(6):E377. PubMed 园

13. Da Costa LA, Arora P, García-Bailo B, Karmali M, El-Sohemy A, Badawi A. The association between obesity, cardiometabolic disease biomarkers and innate immunity-related inflammation in Canadian adults. Diabetes Metab Syndr Obesity 2012;5:347-55.

14. Tremblay MS, Connor Gorber S. Canadian Health Measures Survey: brief overview. Can J Public Health 2007;98 (6):453-6. PubMed 园

15. Giroux S. Canadian Health Measures Survey: sampling strategy overview. Health Rep 2007;18(Suppl):31-6. PubMed 圈

16. Kayaniyil S, Vieth R, Retnakaran R, Knight JA, Qi Y, Gerstein HC, et al. Association of vitamin D with insulin resistance and beta-cell dysfunction in subjects at risk for type 2 diabetes. Diabetes Care 2010;33(6):1379-81. CrossRef 圈 PubMed 圈

17. Scragg R, Sowers M, Bell C. Serum 25-hydroxyvitamin D, diabetes, and ethnicity in the Third National Health and Nutrition Examination Survey. Diabetes Care 2004;27(12):2813-8. CrossRef 国 PubMed 圈

18. Ford ES, Ajani UA, McGuire LC, Liu S. Concentrations of serum vitamin D and the metabolic syndrome among US adults. Diabetes Care 2005;28(5):1228-30. CrossRef 圈 PubMed 国

19. Bourlon PM, Billaudel B, Faure-Dussert A. Influence of vitamin D3 deficiency and 1,25 dihydroxyvitamin D3 on de novo insulin biosynthesis in the islets of the rat endocrine pancreas. J Endocrinol 1999;160(1):87-95. CrossRef 因PubMed 圈

20. Maestro B, Campion J, Davila N, Calle C. Stimulation by 1,25-dihydroxyvitamin D3 of insulin receptor expression and insulin responsiveness for glucose transport in U-937 human promonocytic cells. Endocr J 2000;47(4):38391. CrossRef 因 PubMed 圈

21. Chacko SA, Song Y, Manson JE, Van HL, Eaton C, Martin LW, et al. Serum 25-hydroxyvitamin D concentrations in relation to cardiometabolic risk factors and metabolic syndrome in postmenopausal women. Am J Clin Nutr 2011;94(1):209-17. CrossRef 圈 PubMed 因

22. Del Gobbo LC, Song Y, Dannenbaum DA, Dewailly E, Egeland GM. Serum 25-hydroxyvitamin D is not associated with insulin resistance or beta cell function in Canadian Cree. J Nutr 2011;141(2):290-5. CrossRef 国 PubMed 圈

23. Kayaniyil S, Vieth R, Harris SB, Retnakaran R, Knight JA, Gerstein HC, et al. Association of 25(OH)D and PTH with metabolic syndrome and its traditional and nontraditional components. J Clin Endocrinol Metab 2011;96 (1):168-75. CrossRef 国 PubMed 圈

24. Ramagopalan SV, Heger A, Berlanga AJ, Maugeri NJ, Lincoln MR, Burrell A, et al. A ChIP-seq defined genomewide map of vitamin D receptor binding: associations with disease and evolution. Genome Res 2010;20(10):135260. CrossRef 国 PubMed 圈

25. Heikkinen S, Vaisanen S, Pehkonen P, Seuter S, Benes V, Carlberg C. Nuclear hormone 1alpha,25dihydroxyvitamin D3 elicits a genome-wide shift in the locations of VDR chromatin occupancy. Nucleic Acids Res 2011;39(21):9181-93. CrossRef 国 PubMed 国

26. Querfeld U, Hoffmann MM, Klaus G, Eifinger F, Ackerschott M, Michalk D, et al. Antagonistic effects of vitamin D and parathyroid hormone on lipoprotein lipase in cultured adipocytes. J Am Soc Nephrol 1999;10(10):2158-64. PubMed 国

27. Guillot X, Semerano L, Saidenberg-Kermanac'h N, Falgarone G, Boissier MC. Vitamin D and inflammation. Joint Bone Spine 2010;77(6):552-7. CrossRef 圈 PubMed 圈

28. Hypponen E, Berry D, Cortina-Borja M, Power C. 25-Hydroxyvitamin D and pre-clinical alterations in inflammatory and hemostatic markers: a cross sectional analysis in the 1958 British Birth Cohort. PLoS One 2010;5(5):e10801. CrossRef 圈 PubMed 圈 
Preventing Chronic Disease | Plasma Vitamin D and Biomarkers of Cardiometabolic Dise... Page 7 of 9

29. Amer M, Qayyum R. Relation between serum 25-hydroxyvitamin D and C-reactive protein in asymptomatic adults (from the continuous National Health and Nutrition Examination Survey 2001 to 2006). Am J Cardiol 2012;109 (2):226-30. CrossRef圈 PubMed 圈

30. Vatanparast H, Calvo MS, Green TJ, Whiting SJ. Despite mandatory fortification of staple foods, vitamin D intakes of Canadian children and adults are inadequate. J Steroid Biochem Mol Biol 2010;121(1-2):301-3. CrossRef圈 PubMed圈

\section{Tables}

Table 1. Characteristics of the Study Participants, Canadian Health Measures Survey, 2007-2009a

\begin{tabular}{|c|c|c|c|c|}
\hline Characteristic & All $(n=1,928)$ & Men $(n=927)$ & Women $(n=1,001)$ & P Valueb \\
\hline Hormone use, \% & $15.8(13.0-18.6)$ & $6.3(4.4-8.3)$ & $24.9(20.3-29.5)$ & $<.001$ \\
\hline Age, y & $43.5(43.1-43.9)$ & $42.8(42.0-43.5)$ & $44.2(43.6-44.8)$ & .02 \\
\hline \multicolumn{5}{|l|}{ Race,c \% } \\
\hline White & $84.3(74.5-94.1)$ & $83.7(72.4-95.0)$ & $84.9(75.8-94.0)$ & \multirow{2}{*}{$.72 \mathrm{~d}$} \\
\hline Asiane & $11.4(4.7-18.1)$ & $11.9(3.8-20.0)$ & $10.9(4.2-17.6)$ & \\
\hline Daily energy expenditure, $\mathrm{kcal} / \mathrm{kg} / \mathrm{df}$ & $1.8(1.6-2.0)$ & $2.0(1.8-2.3)$ & $1.6(1.4-1.8)$ & .002 \\
\hline $\mathrm{BMI}, \mathrm{kg} / \mathrm{m} 2 \mathrm{~g}$ & $26.8(26.2-27.4)$ & $27.1(26.5-27.6)$ & $26.6(25.7-27.5)$ & .09 \\
\hline Waist circumference, $\mathrm{cmg}$ & $90.2(88.5-91.9)$ & $94.1(92.5-95.8)$ & $86.4(83.9-88.9)$ & $<.001$ \\
\hline Systolic blood pressure, mm Hgg & $111.2(109.6-112.7)$ & $113.4(112.0-114.9)$ & $108.9(106.7-111.2)$ & $<.001$ \\
\hline Diastolic blood pressure, $\mathrm{mm} \mathrm{Hg}$ & $70.7(69.6-71.8)$ & $73.1(71.9-74.2)$ & $68.4(67.0-69.9)$ & $<.001$ \\
\hline Plasma 25(OH)D, nmol/Lg & $67.5(64.4-70.6)$ & $66.8(62.9-70.6)$ & $68.2(65.3-71.1)$ & .23 \\
\hline Glucose, $\mathrm{mmol} / \mathrm{Lg}$ & $5.1(5.0-5.1)$ & $5.2(5.1-5.3)$ & $5.0(4.9-5.0)$ & $<.001$ \\
\hline Fasting insulin, $\mathrm{pmol} / \mathrm{Lg}$ & $70.9(65.4-76.4)$ & $72.4(66.2-78.6)$ & $69.5(61.7-77.2)$ & .18 \\
\hline HOMA-IRg & $2.4(2.2-2.6)$ & $2.5(2.3-2.7)$ & $2.3(2.0-2.6)$ & .05 \\
\hline Triglycerides, mmol/Lg & $1.3(1.2-1.4)$ & $1.4(1.3-1.5)$ & $1.3(1.1-1.4)$ & .03 \\
\hline Total cholesterol, mmol/L & $4.9(4.7-5.0)$ & $4.8(4.7-4.9)$ & $4.9(4.8-5.0)$ & .04 \\
\hline $\mathrm{HDL}-\mathrm{C}, \mathrm{mmol} / \mathrm{L}^{\mathrm{f}}$ & $1.3(1.3-1.4)$ & $1.2(1.2-1.2)$ & $1.5(1.4-1.5)$ & $<.001$ \\
\hline LDL-C, mmol/Lf & $3.0(2.9-3.1)$ & $3.1(3.0-3.2)$ & $2.9(2.8-3.0)$ & .008 \\
\hline Total:HDL-Cg & $3.9(3.8-4.0)$ & $4.2(4.1-4.3)$ & $3.5(3.4-3.7)$ & $<.001$ \\
\hline ApoA1, $g / L^{f}$ & $1.4(1.4-1.5)$ & $1.3(1.3-1.4)$ & $1.5(1.5-1.6)$ & $<.001$ \\
\hline ApoB, g/Lg & $0.91(0.88-0.93)$ & $0.92(0.89-0.95)$ & $0.89(0.86-0.92)$ & .05 \\
\hline $\mathrm{CRP}, \mathrm{mg} / \mathrm{Lg}$ & $2.3(2.0-2.5)$ & $2.1(1.8-2.4)$ & $2.5(2.2-2.7)$ & .01 \\
\hline Fibrinogen, $\mathrm{mmol} / \mathrm{L}$ & $0.030(0.028-0.031)$ & $0.029(0.027-0.030)$ & $0.030(0.029-0.032)$ & .001 \\
\hline Homocysteine, $\mu \mathrm{mol} / \mathrm{Lg}$ & $7.8(7.3-8.2)$ & $8.6(8.1-9.1)$ & $6.9(6.5-7.4)$ & $<.001$ \\
\hline
\end{tabular}

Abbreviations: BMI, body mass index; 25(OH)D, 25-hydroxyvitamin D; HOMA-IR, homeostatic model assessment of insulin resistance; HDL-C, high-density lipoprotein cholesterol; LDL-C, low-density lipoprotein cholesterol; ApoA1, apolipoprotein A1; ApoB, apolipoprotein B; CRP, C-reactive protein.

a Values expressed as mean (95\% confidence interval) unless otherwise indicated.

b All $P$ values are for tests for differences between sexes. All tests are $t$ tests except for hormone use and race, which are $x^{2}$ tests.

c Race groups were white $(n=1,636)$, Asian $(n=155)$, and other $(n=89)$. Information on race was missing for $48(2.5 \%)$ participants.

$\mathrm{d} \mathrm{X}^{2}$ results for race (white and Asian groups only) by sex. Interpret with caution because of high sampling variability 
Preventing Chronic Disease | Plasma Vitamin D and Biomarkers of Cardiometabolic Dise... Page 8 of 9

associated with Asian group.

e Marginal coefficient of variation (CV) denoting high sampling variability associated with estimate. Use with caution. CV was $27 \%$ for all, $31 \%$ for men, and $28 \%$ for women.

f Variables not normally distributed were square-root transformed for analyses.

g Variables not normally distributed were log transformed for analyses.

Table 2. Cardiometabolic Biomarkers, by Quartiles of Plasma 25Hydroxyvitamin D (25[OH]D), Canadian Health Measures Survey, 20072009a

\begin{tabular}{|c|c|c|c|c|c|c|}
\hline \multirow[b]{2}{*}{ Biomarker } & \multicolumn{4}{|c|}{ 25(OH)D Quartiles } & \multirow[b]{2}{*}{$\beta b$ (SE) } & \multirow{2}{*}{$\begin{array}{c}P \\
\text { Valueb }\end{array}$} \\
\hline & Q1 $(n=476)$ & $Q 2(n=477)$ & Q3 (n = 477) & Q4 $(n=476)$ & & \\
\hline \multicolumn{7}{|l|}{ 25(OH)D, $\mathrm{nmol} / \mathrm{L}$} \\
\hline Range & $11.62-49.91$ & $49.92-65.79$ & $65.80-83.53$ & $83.54-267.07$ & $\mathrm{NC}$ & NC \\
\hline Mean (95\% CI) & $\begin{array}{r}38.1(36.6- \\
39.6)\end{array}$ & $\begin{array}{r}57.9(57.1- \\
58.7)\end{array}$ & $\begin{array}{r}74.4(73.6- \\
75.1)\end{array}$ & $\begin{array}{r}102.5(98.6- \\
106.5)\end{array}$ & $\mathrm{NC}$ & NC \\
\hline Glucose, mmol/Lc & $5.2(5.0-5.3)$ & $5.1(5.0-5.3)$ & $5.0(4.9-5.2)$ & $5.0(4.8-5.1)$ & $\begin{array}{l}-0.02 \\
(0.02)\end{array}$ & .23 \\
\hline Insulin, pmol/Lc & $\begin{array}{r}83.0(67.8- \\
98.3)\end{array}$ & $\begin{array}{r}66.9(59.8- \\
74.0)\end{array}$ & $\begin{array}{r}65.6(57.4- \\
73.9)\end{array}$ & $\begin{array}{r}64.8(57.7- \\
72.0)\end{array}$ & $\begin{array}{l}-0.16 \\
(0.04)\end{array}$ & .003 \\
\hline HOMA-IRc & $2.9(2.4-3.4)$ & $2.3(2.0-2.5)$ & $2.2(1.8-2.5)$ & $2.1(1.9-2.4)$ & $\begin{array}{l}-0.18 \\
(0.05)\end{array}$ & .002 \\
\hline $\begin{array}{l}\text { Triglycerides, } \\
\mathrm{mmol} / \mathrm{Lc}\end{array}$ & $1.5(1.3-1.7)$ & $1.3(1.2-1.5)$ & $1.3(1.1-1.4)$ & $1.2(1.1-1.3)$ & $\begin{array}{l}-0.21 \\
(0.06)\end{array}$ & .004 \\
\hline $\begin{array}{l}\text { Total cholesterol, } \\
\mathrm{mmol} / \mathrm{L}\end{array}$ & $4.9(4.7-5.1)$ & $5.0(4.9-5.2)$ & $4.8(4.6-5.1)$ & $4.6(4.4-4.8)$ & $\begin{array}{l}-0.31 \\
(0.14)\end{array}$ & .05 \\
\hline $\mathrm{HDL}-\mathrm{C}, \mathrm{mmol} / \mathrm{Ld}$ & $1.3(1.2-1.3)$ & $1.3(1.3-1.4)$ & $1.4(1.3-1.5)$ & $1.3(1.3-1.4)$ & $\begin{array}{r}0.02 \\
(0.01)\end{array}$ & .13 \\
\hline $\mathrm{LDL}-\mathrm{C}, \mathrm{mmol} / \mathrm{Ld}$ & $3.1(2.9-3.3)$ & $3.2(3.0-3.3)$ & $3.0(2.8-3.1)$ & $2.7(2.6-2.9)$ & $\begin{array}{l}-0.09 \\
(0.03)\end{array}$ & .02 \\
\hline Total:HDL-Cc & $4.0(3.7-4.3)$ & $4.0(3.8-4.3)$ & $3.7(3.5-3.9)$ & $3.6(3.4-3.8)$ & $\begin{array}{l}-0.09 \\
(0.02)\end{array}$ & .004 \\
\hline ApoA1, g/Ld & $1.4(1.4-1.4)$ & $1.4(1.4-1.5)$ & $1.5(1.4-1.5)$ & $1.4(1.4-1.5)$ & $\begin{array}{r}0.02 \\
(0.01) \\
\end{array}$ & .10 \\
\hline$A p o B, g / L c$ & $\begin{array}{r}0.92(0.86- \\
1.00)\end{array}$ & $\begin{array}{r}0.95(0.91- \\
0.98)\end{array}$ & $\begin{array}{r}0.89(0.85- \\
0.94)\end{array}$ & $\begin{array}{r}0.85(0.82- \\
0.88)\end{array}$ & $\begin{array}{l}-0.07 \\
(0.04)\end{array}$ & .07 \\
\hline $\mathrm{CRP}, \mathrm{mg} / \mathrm{Lc}$ & $2.3(1.7-2.9)$ & $2.3(1.9-2.6)$ & $2.4(2.1-2.7)$ & $2.1(1.7-2.4)$ & $\begin{array}{r}0.09 \\
(0.13)\end{array}$ & .52 \\
\hline Fibrinogen, mmol/L & $\begin{array}{r}0.030(0.028- \\
0.032)\end{array}$ & $\begin{array}{r}0.030(0.028- \\
0.031)\end{array}$ & $\begin{array}{r}0.030(0.028- \\
0.031)\end{array}$ & $\begin{array}{r}0.029(0.028- \\
0.031)\end{array}$ & $\begin{array}{r}0.01 \\
(0.01)\end{array}$ & .56 \\
\hline $\begin{array}{l}\text { Homocysteine, } \\
\mu \mathrm{mol} / \mathrm{Lc}\end{array}$ & $8.0(7.2-8.8)$ & $7.4(7.0-7.9)$ & $8.0(7.4-8.6)$ & $7.6(7.0-8.2)$ & $\begin{array}{l}-0.04 \\
(0.04)\end{array}$ & .39 \\
\hline
\end{tabular}

Abbreviations: SE, standard error; NC, not calculated; CI, confidence interval; HOMA-IR, homeostatic model assessment of insulin resistance; HDL-C, high-density lipoprotein cholesterol; LDL-C, low-density lipoprotein cholesterol; ApoA1, apolipoprotein $\mathrm{A} 1$; ApoB, apolipoprotein B; CRP, C-reactive protein.

a Shown are biomarker crude means (95\% CI) for each 25(OH)D quartile (weighted).

b Regression coefficients $(\beta)$, SEs, and $P$ values for the linear relationship between $25(\mathrm{OH}) \mathrm{D}$ and biomarkers adjusted for sex, waist circumference, physical activity, season, and hormone drug use.

c Where necessary, variables were natural log-transformed for analysis.

d Where necessary, variables were square-root transformed for analysis. 
Preventing Chronic Disease | Plasma Vitamin D and Biomarkers of Cardiometabolic Dise... Page 9 of 9

Table 3. Linear Regression Examining Cardiometabolic Biomarkers and Plasma 25-Hydroxyvitamin D (25[OH]D), by Sex, Canadian Health Measures Survey, 2007-2009a

\begin{tabular}{|c|c|c|c|c|}
\hline \multirow[b]{2}{*}{ Biomarker } & \multicolumn{2}{|l|}{ Men } & \multicolumn{2}{|c|}{ Women } \\
\hline & $\beta^{b}$ (SE) & $P$ Valueb & $\beta \mathrm{b}$ (SE) & $P$ Valueb \\
\hline Glucose, $\mathrm{mmol} / \mathrm{Lc}$ & $-0.03(0.02)$ & .32 & $-0.02(0.02)$ & .35 \\
\hline Insulin, $\mathrm{pmol} / \mathrm{Lc}$ & $-0.21(0.05)$ & .002 & $-0.13(0.06)$ & .05 \\
\hline HOMA-IRc & $-0.24(0.06)$ & .002 & $-0.14(0.06)$ & .03 \\
\hline Triglycerides, mmol/Lc & $-0.26(0.09)$ & .01 & $-0.15(0.08)$ & .09 \\
\hline Total cholesterol, mmol/L & $-0.27(0.16)$ & .12 & $-0.34(0.15)$ & .05 \\
\hline $\mathrm{HDL}-\mathrm{C}, \mathrm{mmol} / \mathrm{Ld}$ & $0.009(0.01)$ & .45 & $0.02(0.02)$ & .27 \\
\hline LDL-C, mmol/Ld & $-0.08(0.04)$ & .09 & $-0.10(0.04)$ & .02 \\
\hline Total:HDL-Cc & $-0.07(0.05)$ & .13 & $-0.10(0.02)$ & .001 \\
\hline ApoA1, g/Ld & $0.008(0.01)$ & .42 & $0.02(0.01)$ & .17 \\
\hline ApoB, g/Lc & $-0.07(0.04)$ & .15 & $-0.07(0.04)$ & .10 \\
\hline $\mathrm{CRP}, \mathrm{mg} / \mathrm{Lc}^{\mathrm{c}}$ & $0.04(0.18)$ & .82 & $0.10(0.14)$ & .52 \\
\hline Fibrinogen, $\mathrm{mmol} / \mathrm{L}$ & $-0.01(0.01)$ & .28 & $0.01(0.01)$ & .19 \\
\hline Homocysteine, $\mu \mathrm{mol} / \mathrm{Lc}$ & $-0.04(0.04)$ & .33 & $-0.03(0.06)$ & .61 \\
\hline
\end{tabular}

Abbreviations: SE, standard error; HOMA-IR, homeostatic model assessment of insulin resistance; HDL-C, high-density lipoprotein cholesterol; LDL-C, low-density lipoprotein cholesterol; ApoA1, apolipoprotein A1; ApoB, apolipoprotein B; CRP, C-reactive protein.

a Shown are values for the linear relationship between 25(OH)D and biomarkers for men and women separately.

b Linear regression adjusted for waist circumference, physical activity, season, and hormone drug use.

c Where necessary, variables were natural log-transformed for analysis.

d Where necessary, variables were square-root transformed for analysis.

\section{Comment on this article at PCD Dialogue}

Learn more about PCD's commenting policy

The opinions expressed by authors contributing to this journal do not necessarily reflect the opinions of the U.S. Department of Health and Human Services, the Public Health Service, the Centers for Disease Control and Prevention, or the authors' affiliated institutions.

The RIS file format is a text file containing bibliographic citations. These files are best suited for import into

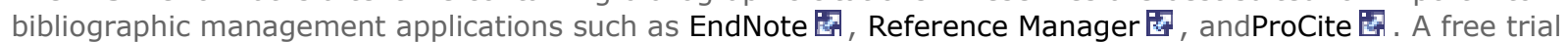
download is available at each application's web site.

For Questions About This Article Contact pcdeditor@cdc.gov

Page last reviewed: June 27, 2013

Page last updated: June 27, 2013

Content source: National Center for Chronic Disease Prevention and Health Promotion

Centers for Disease Control and Prevention 1600 Clifton Rd. Atlanta, GA 30333, USA

800-CDC-INFO (800-232-4636) TTY: (888) 232-6348 - Contact CDC-INFO

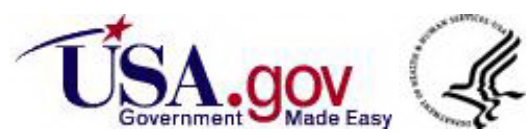

